\title{
Inhibitory Effect of Miconazole on Melanogenesis
}

\author{
Yeun-Ja Mun, ${ }^{*, a}$ Sung-Won LeE, ${ }^{a}$ Hyun-Woo Jeong, ${ }^{b}$ Kwang-Gyu LeE, ${ }^{c}$ Joung-Hoon Kim,,${ }^{a}$ and \\ Won-Hong $\mathrm{WoO}^{a}$ \\ ${ }^{a}$ Department of Herbal Resources, Wonkwang University; Sinyong-dong, Iksan, Jeonbuk 570-749, Korea: ${ }^{b}$ Department of \\ Pathology, College of Oriental Medicine, Dongshin University; Daeho-dong, Naju, Chonnam 520-714, Korea: and \\ ${ }^{c}$ Department of Pathology, College of Oriental Medicine, Woosuk University; Samrye, Wanjukun, Jeonbuk 565-701, \\ Korea. Received November 4, 2003; accepted February 16, 2004
}

\begin{abstract}
Miconazole (MIC), a regional antifungal agent, has been used worldwide in the treatment of superficial mycosis. However, the effect of MIC on skin pigmentation is not known. In this study, we investigated the inhibitory effect of MIC on melanogenesis in B16 melanoma cells. Tyrosinase activity and melanin content were dose dependently decreased by MIC as compared with untreated cells. The level of tyrosinase protein expression was reduced with treatment MIC. A decrease in cell proliferation was observed in B16 cells treated with MIC $30 \mu_{\mathrm{M}}$, indicating that the MIC-induced depigmenting effect was caused by inhibition of melanin synthesis and not by destruction of B16 cells. Furthermore, MIC markedly suppressed $\alpha$-melanocyte stimulating hormone or forskolin-induced tyrosinase activity in B16 cells. Therefore the depigmenting effect of MIC might be due to the inhibition of tyrosinase activity and tyrosinase expression, which eventually slows melanin biosynthesis. These results indicate that MIC may be a useful inhibitor of melanogenesis in B16 cells and suggest that it may have beneficial effects in the treatment of hyperpigmentation disorders such as ephelis and melasma.
\end{abstract}

Key words miconazole; melanin; tyrosinase; pigmentation

Melanin production is principally responsible for skin color and plays an important role in prevention of sun-induced skin injury. Melanin biosynthesis proceeds through a complex series of enzymatic and chemical reactions in melanocytes. ${ }^{1-4)}$ Synthesis of melanin starts from the conversion of amino acid L-tyrosine to 3,4-dihydroxyphenylalanine (L-dopa) and then the oxidation of L-dopa yields dopaquinone by tyrosinase, an enzyme catalyzing the ratelimiting step for melanin biosynthesis. ${ }^{2)}$ Tyrosinase can also function distally in the melanogenic pathway as a 5,6-dihydroxyindole (DHI) oxidase. ${ }^{1)}$ The specific enzyme tyrosinase is deeply involved in abnormal accumulation of melanin pigments. ${ }^{5,6)}$ Various dermatologic disorders result in the accumulation of excessive levels of epidermal pigmentation. These hyperpigmented lentigenes include melasma, age spots or liverspots, and actinic damage (i.e., due to solar ultraviolet irradiation). ${ }^{7-10)}$ Thus the unique biochemical pathways in melanocytes responsible for melanogenesis provide rational mechanism-based means for developing both pharmacologic regulators of pigmentation and cytotoxic chemotherapeutic drugs for the treatment of melanoma.

Opportunistic fungal infections have increased dramatically in recent years as a result of increased immunosuppression associated with AIDS, organ and bone marrow transplantation, and aggressive treatment of cancer and autoimmune disorders. Miconazole (MIC), an antifungal imidazole, has been used world-wide in the treatment of superficial mycosis. Many clinicians believe that regional treatment with MIC is a relatively effective in the treatment of most mycotic infections. ${ }^{1-14)}$

It has recently been reported that systemic and/or regional treatment with antimycotics, especially azole derivatives such as ketoconazole and bifonazole, are effective for patients with atopic dermatitis. ${ }^{15,16)}$ Fluconazole has been reported to promote reepithelization in full-face carbon dioxide laser skin resurfacing. ${ }^{1718)} \mathrm{MIC}$ has also been reported to have biologic and pharmacologic activities such as antitumor ef- fects. ${ }^{19,20)}$ However, to the best of our knowledge there have been no reports on the effect of MIC as a local therapeutic agent on skin pigmentation.

Therefore the present study was designed to investigate the effect of MIC on melanogenesis in B16 melanoma cells, particularly its specific effects on tyrosinase activity and on melanin formation.

\section{MATERIALS AND METHODS}

Reagents and Supplies Fetal bovine serum (FBS) was purchased from HyClone Laboratories (Logan, U.K.). Dulbecco's modified Eagle's medium (DMEM) was obtained from Gibco (Grand Island, NY, U.S.A.). All other chemicals, including MIC nitrate, bovine serum albumin (BSA), Triton $\mathrm{X}-100$, phenylmethylsulfonyl fluoride (PMSF), dimethyl sulfoxide (DMSO), trichloroacetic acid (TCA), synthetic melanin, $\alpha$-melanocyte stimulating hormone (MSH), kojic acid, aprotinin, forskolin, peroxidase-conjugated anti-mouse antibody, and L-DOPA were purchased from Sigma Chemical Co. (St. Louis, MO, U.S.A.).

Cell Culture and Treatment B16 murine melanoma cells were routinely cultured in DMEM supplemented with $10 \% \mathrm{FBS}$ in air containing $5 \% \mathrm{CO}_{2}$ at $37^{\circ} \mathrm{C}$. After incubation, the medium was changed every $2 \mathrm{~d}$. A stock solution of MIC was made at the concentration of $30 \mathrm{~mm}$ in DMSO was added to the cell culture at final concentrations of 3,10 , and $30 \mu \mathrm{M}$. After 48- or 72-h treatment with MIC, the cells were harvested, counted, and used for the various assay procedures described below.

Cell Growth Assay The effects of MIC on cell growth were measured by directly counting the number of cells using trypan blue dye exclusion. B16 cells were plated at $3 \times 10^{4}$ cells in 12-well plates. The next day, the medium was changed and MIC $(3-30 \mu \mathrm{M})$ was added. Control cells were treated with DMSO at a final concentration of $0.05 \%(\mathrm{v} / \mathrm{v})$. At the end of incubation, cells were harvested and number of 
live cells was counted with a hemocytometer.

Determination of Tyrosinase Activity Tyrosinase activity was determined using a modification of the method described by Martinez-Esparza et al. ${ }^{21)}$ In brief, B16 cells were cultured at $1 \times 10^{5}$ cells in 6 -well plates. After $24 \mathrm{~h}$, the cells were treated with various concentrations of MIC ranging from 3 to $30 \mu \mathrm{M}$. The cells were harvested by trypsinization and washed three times with ice-cold phosphate-buffered saline (PBS) by centrifugation at $1000 \times \boldsymbol{g}$ for $5 \mathrm{~min}$. The cells were lysed in $0.1 \mathrm{M}$ sodium phosphate buffer $(\mathrm{pH} 7.0)$ containing 1\% Triton X-100 and 0.1 mM PMSF. After incubation for $30 \mathrm{~min}$ to release tyrosinase from the melanosome membrane, cellular extracts were clarified by centrifugation at $10000 \times \boldsymbol{g}$ for $25 \mathrm{~min}$ at $4{ }^{\circ} \mathrm{C}$. The reaction mixture consisted of $0.05 \%$ L-DOPA solution and $30 \mu \mathrm{g}$ of protein cell extract in a total volume of $0.2 \mathrm{ml}$ sodium phosphate buffer (0.1 M, pH 7.0). Protein content was measured using the BioRad Protein Assay Kit (Bio-Rad, Richmond, CA, U.S.A.) with BSA as the standard. Dopachrome formation was monitored by measuring absorbance at the wavelength of $405 \mathrm{~nm}$ in a microplate reader. Absorbance was read every $10 \mathrm{~min}$ for $1 \mathrm{~h}$ at $37^{\circ} \mathrm{C}$.

Assay of Melanin Content Determination of melanin content was performed using the modified method of Hosoi et al. ${ }^{22)} \mathrm{B} 16$ cells were cultured at $1 \times 10^{5}$ cells in 6 -well plates. After $24 \mathrm{~h}$, the cells were treated with various concentrations of MIC ranging from 3 to $30 \mu \mathrm{M}$ for $72 \mathrm{~h}$. The cells were harvested by trypsinzation. After washing twice with PBS, samples were air-dried and dissolved in $200 \mu \mathrm{l}$ of $1 \mathrm{~N}$ $\mathrm{NaOH}$ containing $10 \%$ DMSO. Samples were then heated at $80^{\circ} \mathrm{C}$ for $1 \mathrm{~h}$ and cooled; the amount of melanin was determined spectrophotometrically based on absorbance at $475 \mathrm{~nm}$.

Western Blot Analysis For tyrosinase immunoblot detection, B16 cells were cultured at $1 \times 10^{5}$ cells/well. After $24 \mathrm{~h}$, the cells were treated with MIC at concentrations of 3, 10 , and $30 \mu \mathrm{M}$ for $48 \mathrm{~h}$. The cells were lysed in phosphate buffer, $\mathrm{pH} 6.8$, containing $1 \%$ Triton $\mathrm{X}-100,100 \mathrm{IU} / \mathrm{ml}$ of aprotinin, and $1 \mathrm{~mm} 4$-(2-aminoethyl)-benzene-sulfonyl fluoride (AEBSF). Equal amounts of proteins $(30 \mu \mathrm{g} /$ lane $)$ were separated on $10 \%$ sodium dodecyl sulfate (SDS)-7.5\% polyacylamide gels and transferred to a nitrocellulose membrane (Amersham, U.K.). The membranes were saturated with 5\% powdered skim milk in a saline buffer, and tyrosinase was detected with the polyclonal anti-tyrosinase antibody (sc15341, Santa Cruz, CA, U.S.A.) diluted $1: 500$ in the saturation buffer, and with a secondary peroxidase-conjugated antimouse antibody at a 1:2000 dilution. After antibody incubation, the membranes were washed three times using a solution containing $0.05 \%$ Triton $\mathrm{X}-100$ and $0.5 \%$ powdered skim milk in a saline buffer. The blot was developed using the ECL system from Amersham. Equal loading of total protein was confirmed by reprobing membranes for actin (sc1616).

Statistical Analysis The values are expressed as mean \pm standard deviation (S.D.). All data were examined for statistical significance of differences using Student's $t$-test.

\section{RESULTS}

Effect of MIC on Cell Proliferation To investigate the

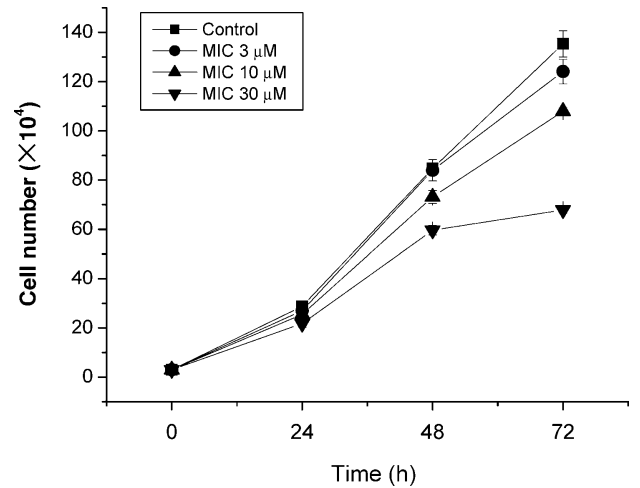

Fig. 1. Effect of MIC on Cell Number in B16 Cells

Dose-dependent inhibition of cell growth was observed in B16 cells treated with MIC. B16 cells were cultured at $3 \times 10^{4}$ cells $/$ well. After $24 \mathrm{~h}$, the cells were treated with various concentrations of MIC ( 3 to $30 \mu \mathrm{M}$ ). Three samples were analyzed in each group and the results are expressed as mean \pm S.D.

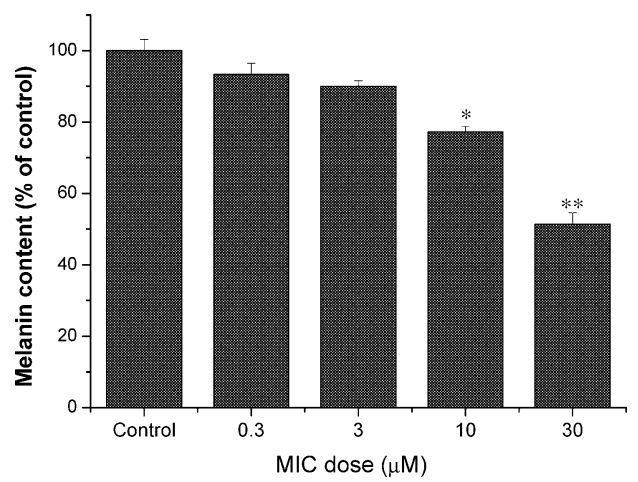

Fig. 2. Inhibitory Effect of MIC on Melanin Synthesis in B16 Cells

B16 cells were cultured at $1 \times 10^{5}$ cells/well. After $24 \mathrm{~h}$, the cells were treated with MIC $(0.3$ to $30 \mu \mathrm{M})$ and melanin content was determined $72 \mathrm{~h}$ later. Data are expressed as $\%$ of control, and each column represents the mean \pm S.D. of four determinations. Significantly different from the control value: $* p<0.05, * * p<0.01$.

effect of MIC on cell proliferation, B16 cells were treated with various concentrations ( 3 to $30 \mu \mathrm{M}$ ) of $\mathrm{MIC}$ for $72 \mathrm{~h}$ and the number of cells was determined (Fig. 1). As shown in Fig. 1, MIC induced dose-dependent inhibition of cell growth in B16 cells. The inhibitory effects on B16 cells were less profound at a lower dose $(<10 \mu \mathrm{M})$ of MIC, while significant cell growth arrest was observed at MIC $30 \mu \mathrm{M}$. Up to the dose of $30 \mu \mathrm{M}$, MIC treatment did not result in cell necrosis and detachment from the culture plates as viewed under light microscopy (data not shown).

Effect of MIC on Melanin Production To provide more direct evidence that MIC inhibits melanogenesis, we determined its effects on melanin production in B16 cells. The melanin content of B16 cells treated with MIC are shown in Fig. 2. Treatment with MIC $0.3,3,10$, or $30 \mu \mathrm{M}$ for $72 \mathrm{~h}$ induced dose-dependent inhibition $(7 \%$ at $3 \mu \mathrm{M}, 23 \%$ at $10 \mu \mathrm{M}$, and $49 \%$ at $30 \mu \mathrm{M}$ ) of melanin formation by B16 cells as compared with controls $(100 \%)$.

Effect of MIC on Tyrosinase Activity Tyrosinase activities in B16 cells treated with MIC also decreased in a manner correlating well with the inhibitory effect on melanin production (Fig. 3). After 48-h incubation with MIC, tyrosinase activity was suppressed to $24 \%$ at $3 \mu \mathrm{M}, 32 \%$ at $10 \mu \mathrm{M}$, and $95 \%$ at $30 \mu \mathrm{M}$ compared with control. B16 cells treated with MIC $30 \mu \mathrm{M}$ MIC exhibited a marked inhibitory effect on 


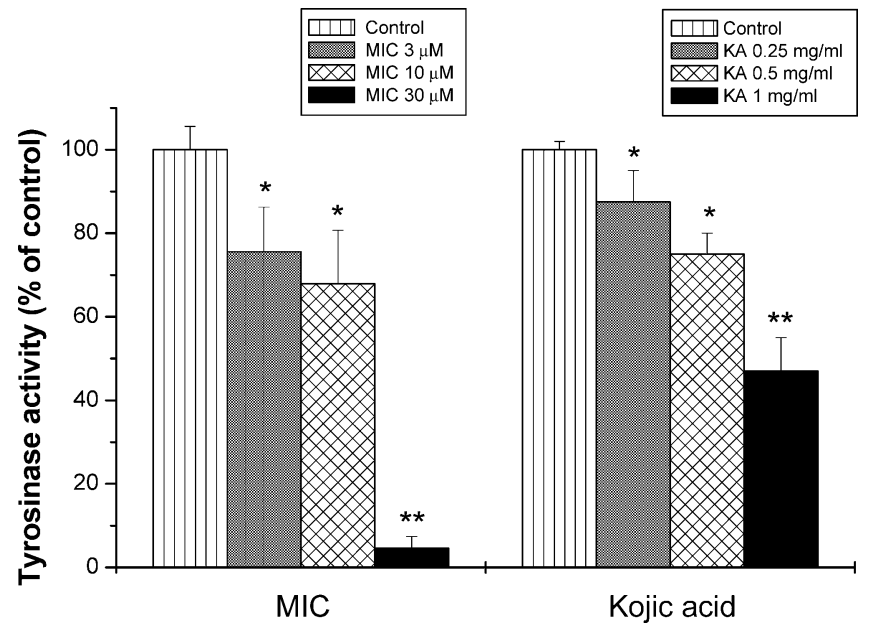

Fig. 3. Inhibitory Effects of MIC and Kojic Acid (KA) on Tyrosinase Activity in B16 Cells

B16 cells were cultured at $1 \times 10^{5}$ cells/well. After $24 \mathrm{~h}$, the cells were treated with MIC ( 3 to $30 \mu \mathrm{M})$ and kojic acid $(0.25$ to $1 \mathrm{mg} / \mathrm{ml})$. The tyrosinase activity in B16 cells was determined $48 \mathrm{~h}$ later. Data are expressed as \% of control, and each column represents the mean \pm S.D. of four determinations. Significantly different from the control value: $* p<0.05, * * p<0.01$

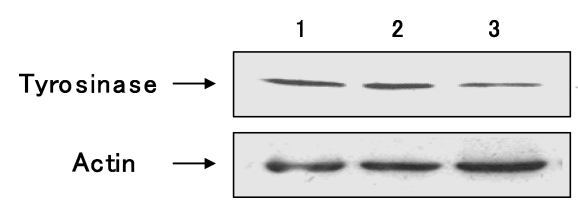

Fig. 4. Inhibitory Effect of MIC on Tyrosinase Protein Expression in B16 Cells

Western blotting of tyrosinase in B16 melanoma cells with or without MIC treatment for $72 \mathrm{~h}$. 1, Control; 2, MIC $10 \mu \mathrm{m} ; 3$, MIC $30 \mu \mathrm{M}$. Arrows indicate representative bands, and significant changes were noted. Similar results were obtained in repeated experiments.

tyrosinase activity. Kojic acid was used as a standard agent and also inhibited the tyrosinase activity of B16 cells.

Effect of MIC on Tyrosinase Protein Expression To scrutinize further the role of tyrosinase in B16 cells treated with MIC (3-30 $\mu \mathrm{M})$, the level of tyrosinase protein expression was determined (Fig. 4). As shown in Fig. 4, the protein level of tyrosinase was reduced in the MIC-treated cells.

Effect of MIC on $\alpha$-MSH or Forskolin-Induced Pigmentation To examine the action of MIC on skin hyperpigmentation, we investigated its effects in B16 cells stimulated with $\alpha$-MSH or forskolin, which are the best characterized biologically relevant agents inducing melanogenesis. After 48-h incubation with $\alpha$-MSH or forskolin, tyrosinase activity increased 2.3-fold or 6-fold, respectively, compared with controls (Fig. 5). However, these increases were markedly suppressed in the presence of MIC.

\section{DISCUSSION}

The purpose of the present study was to investigate the inhibitory effects of MIC on melanin formation, which is closely related to pigmentation of the skin. Melanogenesis, a major differentiated function of melanocytes, plays an important role in protecting skin from sun-related injuries and is principally responsible for skin color. ${ }^{1-4)}$ Tyrosinase plays a critical regulatory role in melanin biosynthesis and it is suggested that tyrosinase activity is pivotal. ${ }^{2,23)}$ Thus numerous

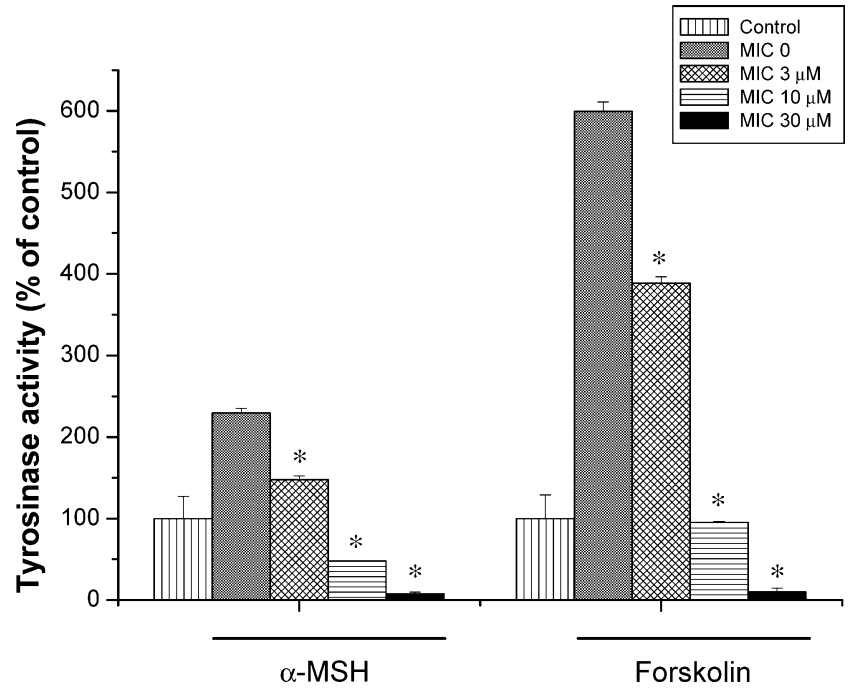

Fig. 5. Inhibitory Effects of MIC on Tyrosinase Activity in B16 Cells Stimulated by $\alpha$-MSH or FSK

B16 cells growing in serum-containing medium $\left(1 \times 10^{5}\right.$ cells/well $)$ were treated with MIC ( 3 to $30 \mu \mathrm{M}$ ). After $30 \mathrm{~min}$, the cells incubated with $10 \mathrm{~nm} \alpha$-MSH or forskolin $20 \mu \mathrm{M}$. The tyrosinase activity in B16 cells was determined $48 \mathrm{~h}$ later. Data are expressed as $\%$ of control, and each column represents the mean \pm S.D. of four determinations. Significantly different from the $\alpha$-MSH alone value or FSK alone value: $* p<0.01$.

studies have focused on characterizing the melanogenic pathways that regulate tyrosinase activity in melanocytes. ${ }^{24,25)}$ However, the effects of MIC associated with various in vitro and in vivo trials on tyrosinase activity are currently not being investigated.

Our study demonstrated that melanin formation and tyrosinase activity were clearly suppressed by MIC at the concentration of $30 \mu \mathrm{M}$. This study was designed using the dose of MIC that shows effective antifungal activity. Recently, Wu et $a l$. have reported that significant cell growth arrest and cytotoxic effects were only observed in human normal keratinocytes treated with higher doses of MIC $(>40 \mu \mathrm{M}) 48 \mathrm{~h}$ later. ${ }^{20)}$ They also found that MIC $(20 \mu \mathrm{M})$ induced a significant accumulation $(>85 \%)$ of cells in the $\mathrm{G} 0 / \mathrm{G} 1$ phase of the cell cycle in human COLO205 cells. ${ }^{20)}$ We observed that the inhibition of cell growth in B16 cells was induced by MIC $30 \mu \mathrm{M}$. These results suggest that the MIC-induced depigmenting effect is caused by inhibition of melanin synthesis and cytostatic effects, not by the destruction of melanocytes.

A positive relationship between tyrosinase activity and tyrosinase mRNA levels in murine melanoma cells has been reported, although no correlation between them was observed in human melanocytes or in human/murine melanoma cells. ${ }^{26-29)}$ Using melanogenic regulatory agents, 12-Otetradecanoylphorbol 13-acetate was shown to decrease melanogenesis and to down-regulate the abundance of tyrosinase mRNA, ${ }^{27,28)}$ while cyclic adenosine monophosphate was shown to increase melanogenesis and to up-regulate tyrosinase mRNA levels. ${ }^{26,28)}$ Induction of melanogenesis in B16 cells was characterized by the stimulation of tyrosinase activity resulting from an increase in tyrosinase protein expression. ${ }^{30)}$ In this study, we observed that tyrosinase activity and tyrosinase protein expression level are significantly suppressed by MIC. These results suggest that the depigmenting effects of MIC are caused by inhibition of tyrosinase activity 
and tyrosinase expression, which eventually slow melanin biosynthesis.

Compelling evidence has been gathered indicating that pro-opiomelanocortin peptides and cAMP also play key roles in the regulation of skin and hair pigmentation in humans. Skin hyperpigmentation has been reported in patients with Addison disease, which is characterized by the overproduction of adrenocorticotropic hormone (ACTH). ${ }^{31,32)}$ In cultured human melanocytes and mouse melanoma cells, $\alpha$ $\mathrm{MSH}$ and $\mathrm{ACTH}$ up-regulate melanogenesis and dendricity. ${ }^{33-35)}$ These effects can be mimicked by pharmacologic cAMP-elevating agents such as forskolin, cholera toxin, or isobutylmethylxanthine, ${ }^{23)}$ i.e., $\alpha$-MSH binds to an $\alpha$ s-coupled receptor and increases the intracellular level of cAMP. ${ }^{33-35)}$ This hormone strongly stimulates the local pigmentation in humans. ${ }^{36}$ Kuzumaki et al. also showed that cAMP-elevating agents increase tyrosinase activity levels. ${ }^{4)}$ These observations emphasize the crucial role of cAMP and tyrosinase activity in the regulation of melanogenesis. In addition, we also showed that MIC markedly inhibits the tyrosinase activity of B16 melanoma cells stimulated by $\alpha$-MSH or forskolin in a dose-dependent manner. Our study demonstrated that MIC blocked $\alpha$-MSH- or forskolin-stimulated melanogenesis mediated through the activation of the cAMP pathway. These observations imply that the depigmenting effect of MIC may be more effective on active melanocytes.

MIC was demonstrated to be an inhibitor of cytochrome P450-dependent steroidogenic enzymes. ${ }^{37)}$ MIC has been found to attenuate the increase in cerebral blood flow elicited by glutamate. ${ }^{38)}$ MIC has also been demonstrated to be a plasma membrane $\mathrm{H}^{(+)}$ATPase blocker and it affects the intracellular calcium levels in HL60 cells. ${ }^{39)}$ Moreover, the inhibitory effects of MIC on conjugative metabolism using rabbit liver microsomes in vitro have been demonstrated. ${ }^{40,41)}$ Tyrosinase (monophenol oxygenase, EC 1.14.18.1) is a membrane-bound glycoprotein. ${ }^{2}$ ) Treatment of cultured melanoma cells with $N$-glycosylation inhibitors is known to result in retardation of melanosome maturation, inhibition of melanosomal enzyme activities, or suppression of melanogenesis. ${ }^{42,43)}$ This suggests that MIC may have a regulatory role in glycosylation at several steps in the melanogenic pathway. In this study, we did not attempt to measure whether MIC modifies the glycosylation pattern of tyrosinase.

In conclusion, our results clearly demonstrate that MIC is an effective inhibitor of tyrosinase activity and tyrosinase protein expression in B16 melanoma cells, which eventually slow melanin biosynthesis. These results indicate that MIC may be a useful inhibitor of melanogenesis and suggest that it may have beneficial effects in the treatment of hyperpigmentation disorders such as ephelis and melasma.

Acknowledgments This work was supported by a grant from the Oriental Medicine R\&D Project (02-PJ1-PG4PT05-0003), Ministry of Health \& Welfare, Republic of Korea, and partially by a grant from Wonkwang University in 2003.

\section{REFERENCES}

1) Körner A. M., Pawelek J. M., Science, 217, 1163-1167 (1982).

2) Hearing V. J., Jimenez M., Int. J. Biochem., 19, 1141-1147 (1987).

3) Prota G., Med. Res. Rev., 8, 525-556 (1988).
4) Kuzumaki T., Matsuda A., Wakamatsu K., Ito S., Ishikawa K., Exp. Cell. Res., 207, 33-40 (1993).

5) Mishima Y., Pigment Cell Res., 7, 376-387 (1994).

6) Virador V., Matsunaga N., Matsunaga J., Valencia J., Oldham R. J., Kameyama K., Peck G. L., Ferrans V. J., Vieira W. D., Abdel-Malek Z. A., Hearing V. J., Pigment Cell Res., 14, 289-297 (2001).

7) Jimbow K., Horikoshi T., Am. J. Dermatopathol., 4, 413-420 (1982).

8) Gilchrest B. A., Park H. Y., Eller M. S., Yaar M., Photochem. Photobiol., 93, 1-10 (1996).

9) Haddad M. M., Xu W., Medrano E. E., J. Invest. Dermatol. Symp. Proc., 3, 36-40 (1988).

10) Halder R. M., Nootheti P. K., J. Am. Acad. Dermatol., 48, S143-148 (2003).

11) Brincker H., Scand. J. Infect. Dis., 8, 117-120 (1976).

12) Brincker H., Acta Med. Scand., 204, 123-128 (1978).

13) Morgans M. E., Thomas M. E. M., Mackenzie D. W. R., BMJ, 14, 100-101 (1979).

14) Diehl K. B., Am. Family Phys., 54, 1687-1692 (1996).

15) Back O., Scheynius A., Johansson S. G., Arch. Dermatol. Res., 287, 448-541 (1995).

16) Lintu P., Savolainen J., Kortekangas-Savolainen O., Kalimo K., Allergy, 56, 512-751 (2001).

17) Manuskiatti W., Fitzpatrick R. E., Goldman M. P., Krejci-Papa N., J. Am. Acad. Dermatol., 40, 77-84 (1999).

18) Conn H., Nanda V. S., Lasers Surg Med., 26, 201-207 (2000).

19) Wang Y. J., Jeng J. H., Chen R. J., Tseng H., Chen L. C., Liang Y. C., Lin C. H., Chen C. H., Chu J. S., Ho W. L., Ho Y. S., Mol. Carcinog., 34, 199-210 (2002).

20) Wu C. H., Jeng J. H., Wang Y. J., Tseng C. J., Liang Y. C., Chen C. H., Lee H. M., Lin J. K., Lin C. H., Lin S. Y., Li C. P., Ho Y. S., Toxicol. Appl. Pharmacol., 180, 22-35 (2002).

21) Martinez-Esparza M., Jimenez-Cervantes C., Solano F., Lozano J. A., Garcia-Borron J. C., Eur. J. Biochem., 255, 139-146 (1998).

22) Hosoi J., Abe E., Suda T., Kuroki T., Cancer Res., 45, 1474-1478 (1985).

23) Busca R., Ballotti R., Pigment Cell Res., 13, 60-69 (2000).

24) Dooley T. P., Gadwood R. C., Kilgore K., Thomasco L. M., Skin Pharmacol., 7, 188-200 (1994).

25) Curto E. V., Kwong C., Hermersdorfer H., Glatt H., Santis C., Virador V., Hearing V. J., Jr., Dooley T. P., Biochem. Pharmacol., 57, 663-672 (1999).

26) Hogason G. E., Ledwitz-Rigby F., Davidson R. L., Fuller B. B., Somatic Cell. Mol. Genet., 15, 255-263 (1989).

27) Fuller B. B., Niekrasz I., Hoganson G. E., Mol. Cell Endocrinol., 72, $81-87$ (1990).

28) Naeyaert J. M., Eller M., Gordon P. R., Park H. Y., Gilchrest B. A., Br. J. Dermatol., 125, 297-303 (1991).

29) Ando H., Itoh A., Mishima Y., Ichihashi M., J. Cell Physiol., 163, 608-614 (1995).

30) Englaro W., Bertolotto C., Busca R., Brunet A., Pages G., Ortonne J. P., Ballotti R., J. Biol. Chem., 273, 9966-9970 (1998).

31) Takahashi T., Ishii S., Atsumi S., Mita H., Hayashi T., Adachi M., Hinoda Y., Toyoshima N., Imai K., Rinsho Ketsueki, 37, 867-869 (1996).

32) Lin S. Y., Chang C. L., Jap T. S., Lin H. D., Won J. G., Zhonghua Yi Xue Za Zhi, 61, 170-174 (1998).

33) Wong G., Pawelek J., Nature (London), 241, 213-215 (1973).

34) Fuller B. B., Viskochil D. H., Life Sci., 24, 2405-2416 (1979).

35) Jimenez M., Kameyama K., Maloy W. L., Tomita Y., Hearing V. J., Proc. Natl. Acad. Sci. U.S.A., 85, 3830-3834 (1988).

36) Hunt G., Donatien P. D., Lunec J., Todd C., Kyne S., Thody A. J., Pigment Cell Res., 7, 217-221 (1994).

37) Ayub M., Levell M. J., J. Steroid Biochem., 32, 515-524 (1989).

38) Bhardwaj A., Northington F. J., Carhuapoma J. R., Falck J. R., Harder D. R., Traystman R. J., Koehler R. C., Am. J. Physiol. Heart. Circ. Physiol., 279, H1616-1624 (2000).

39) Flaadt H., Schaloske R., Malchow D., J. Biosci., 25, 243 -252 (2000).

40) Asgari M., Back D. J., J. Infect. Dis., 172, 1634-1636 (1995).

41) Sawamura R., Sato H., Kawakami J., Iga T., Biol. Pharm. Bull., 23, 669-671 (2000).

42) Imokawa G., Mishima Y., J. Invest. Dermatol., 83, 196-201 (1984).

43) Takahashi H., Parsons P. G., J. Invest. Dermatol., 98, 481-487 (1992). 